\title{
Representasi Politik Opini Publik terhadap Pemilukada Sumatra Barat 2010 pada Koran Singgalang dan Program Sumbar Satu
}

\author{
Muhammad Thaufan A \\ Prodi Komunikasi, Universitas Andalas, Padang \\ (Mahasiswa doctoral GSID-Nagoya University Japan)
}

\begin{abstract}
This paper aims to discover political representation of the lokal media namely Harian Singgalang regarding public opinion during the election in West Sumatra Indonesia. Furthermore, the complexity of media power will be discussed through such television program and the newspaper 's headline and special report. By using case study approach and critical discourse analysis of Norman Fairclough in analyzing text, discoursive practice, and socio-cultural practice, it can be noted that political public opinion had been fully articulated in such lokal media representing collaboration actors and institution among media, politicians and lokal people.

Political opinion could be sensed in the program "Menuju Sumbar Satu Padang TV" and located in the headlines and special report of Harian Singgalang during April-August 2010. Representation of political opinion in both Padang TV and Singgalang indicated media logic and also vested interested among such media and elites in order to maintain lokal democracy by spreading politically strategic information, persuading the audience, making the myth of good impression in order to win the election.

Menuju Sumbar Satu Padang TV has depicted campaign strategy of some governors candidates while headlines and special report of Singgalang have extremely covered all candidates and transformed those dynamic public sphere for political consensus among media, politicians and the audience in promoting lokal democracy in West Sumatra 2010.
\end{abstract}

Key Words : Mass Media, Media Power, Public Opinion, Representation, Democracy

\begin{abstract}
Abstrak
Tulisan ini menyingkap tabir representasi politis media lokal yaitu Padang TV dan Harian Singgalang terkait opini public dalam proses Pemilukada Sumatera Barat 2010. Lebih jauh, kuasa media dipaparkan melalui program televisi, headline dan laporan khusus media tersebut. Dengan pendekatan studi kasus dan analisis wacana kritis pada level teks, wacana dan sosiokultural ditemukan opini public politis telah diartikualsikan secara maksimal oleh media, elit dan masyarakat pemilih.

Opini public politis dapat disaksikan dalam program Menuju Sumbar Satu Padang TV dan terbaca dalam Headline serta laporan khusus Singgalang selama periode April hingga Agustus 2010. Representasi opini politis ini menandakan kedigdayaan logika media dan juga kepentingan terselubung dari media dan elit untuk menjaga demokrasi lokal dengan penyebaran informasi strategis, meyakinkan pemilih, dan membuat kesan baik demi memenangkan pemilihan.

Menuju Sumbar satu memotret kampanye para kandidat Gubernur sedang Headline dan Liputan Khusus Singgalang mengkover semua kandidat dengan baik dan menjadi ruang public dinamis bagi media, politisi dan pemilih dalam mendukung demokrasi lokal di Sumatra Barat
\end{abstract}

Kata Kunci : media massa, kuasa media, opini public, representasi, demokrasi 


\section{Pendahuluan}

Media massa mainstream terutama surat kabar dan televisi sebelum massifnya media sosial berperan penting dalam hajatan politik di Indonesia. Media massa menyajikan informasi kepada publik luas pelbagai isu politik hangat aktual, menciptakan ruang debat seperti polemik pilkada langsung atau tak langsung seperti saat ini, dan juga mengartikulasikan ragam aspirasi. Strategi komunikasi dan aksi politik membentuk opini publik dalam pemilihan Gubernur, Kepala Daerah dan event politik lainnya sungguh tak dapat lagi dipisahkan dari peran strategis media yang menjadi makin penting. Strategi politik meniscayakan media massa tak hanya menciptakan realitas baru yang politis, mengintensifkan agenda publik tetapi juga dipicu menguatnya nalar media saat ini di era teater debat dan praksis demokrasi di Indonesia.

Media massa menjelang momentum politik besar seringkali menampilkan program acara dan rubrik berita kepada masyarakat yang menghadirkan kandidat dan pengamat politik berupa diskusi politik, pidato, iklan politik, debat kandidat, poling opini publik, dan bahkan persoalan pencitraan politik hingga wilayah privasi kontestan politik (Brants and Voltmer, 2011). Media massa dengan segenap sumber daya dan kepentingannya mencoba meragamkan dan mengarahkan opini publik untuk memengaruhi khalayak dalam proses politik (Pawito, 2008; Gurevitch, et al, 2005 ).

Tulisan mengenai proses pemilihan Gubernur, Walikota dan Bupati 2010 yang telah berlangsung secara serentak di Sumatara Barat ini penting dan relevan untuk memahami rekam jejak dan karakter hajatan politik di level lokal dalam relasinya dengan media massa lokal untuk membangun argumentasi pentingnya partisipasi politik lokal demi masa depan demokrasi di Sumatra Barat. Pemilihan tersebut menjadi penentu transisi demokrasi lokal yang masih sangat krusial untuk tak terjadinya penyimpangan dan kemunduran dalam gaya politik otoriter masa lalu (Zakaria, 2004) dan munculnya elit status quo di level lokal (Hadis, 2005).

Di samping pemilihan di level provinsi, kabupaten dan kota yang menggelar Pilkada serentak di Provinsi Sumbar 2010 meliputi Agam, Padang Pariaman, Solok, Solok Selatan, Pesisir Selatan, Tanah Datar, Sijunjung, Limapuluh Kota, Pasaman Barat, Pasaman, Dharmasraya dan Kota Solok serta Bukittinggi. Momentum politik ini memunculkan kandidat-kandidat Gubernur, Walikota dan Bupati yang berkompetisi merebut hati masyarakat (http://www.padangtoday.com).

Penelitian kualitatif empiris ini meneliti kasus Koran lokal Harian Singgalang dan program Sumbar satu didasarkan pada metode studi kasus dan wacana kritis dengan perspektif bahwa media massa lokal tersebut memiliki peran demokratis dalam memotret dan mengatur irama politik lokal serta memediasi kedigdayaan elit politik dalam merekonstruksi strategi komunikasi politik. Representasi media massa ini pada taraf tertentu telah membawa perubahan cara pandang publik dalam memahami politik dengan bantuan media, memotret dinamika partisipasi politik publik dan mendorong menguatnya konsolidasi demokrasi lokal di Sumatra Barat. Tetapi, elit politik lokal harus diwaspadai sebagai salah satu pemicu mundurnya demokrasi di Indonesia (Hadis, 2005; Kimura, 2011).

\section{Konseptualisasi Opini Public di Media Massa Lokal}

Setiap masyarakat memiliki sejumlah insitusi baik tradisional maupun 
modern yang menyajikan informasi dan penafsiran atas berbagai peristiwa. Institusi ini memantau kondisi lingkungan, mendeteksi berbagai ancaman, masalah, peluang dan dukungan, serta memberitahukannya kepada para warga masyarakat agar dapat menyesuaikan diri. Media dalam pandangan liberal adalah salah satu contoh institusi sosial tersebut, yang menyatu dengan lingkungan kebudayaan, otonom dan meragamkan pandangan serta mengembangkan kesadaran demokrasi warga (Gurevitch et al, 2005).

Media massa dapat dimaknai bukan hanya alat-alat teknologis yang membawa pesan (McLuhan, 1964), memperluas cakrawala kebangsaan dan mempercepat kehidupan manusia modern/rasional (Anderson, 2006), melainkan juga sebagai pranata sosial (Gurevitch, et al, 2005). Sebagai pranata sosial, media massa menjalankan tugas yang oleh McQuail (1997) disebut silent characteristic, yakni meliputi penggunaan teknologi pembuatan dan penyebarluasan pesan-pesan secara massif, organisasi dan regulasi yang bersifat sistematis, arah pesan bagi khalayak yang besar dan luas, tak diketahui secara personal, dan bebas dalam mengakses atau mengelak.

Media massa secara politis diyakini sangat powerful, persuasif dan berpengaruh sejak perang dunia I. Tentu pandangan ini dikritik lebih jauh oleh pemikir pandangan baru seperti Jay Blumler yang mengafirmasi efek terbatas media atau pendukung agenda setting seperti McCombs maupun kaum tradisi Marxist yang percaya media hanya melegitimasi kelompok dominan. Walaupun, jalan tengah bisa ditemukan bahwa media untuk beberapa taraf punya efektivitas dan pengaruhnya tergantung konteks social dan dinamika kasus di mana semua kemungkinan dapat terjadi (Gurevitcth, et al, 2005).
Dalam pandangan liberal, media bekerja demokratis menyajikan informasi, analisis, penafsiran dan pemberian makna terhadap peristiwa, pewarisan nilai dari generasi ke generasi, memengaruhi pendapat dan sikap khalayak aktif, memengaruhi khalayak dalam menentukan apa yang harus ditentukan dan pendefinisian persoalan-persoalan (agenda setting), serta mendorong lahirnya partisipasi politik (Pawito, 2007). Dalam kaitan dengan demokrasi, seperti dikatakan oleh Curran (2002), media massa dapat berperan dalam penyebarluasan informasi yang beragam perspektif, mewakili khalayak, memberikan tempat dinyatakannya pendapat dari berbagai kelompok masyarakat yang berbeda sehingga ada debat publik yang dinamis, mendorong pemecahan masalah yang ada di dalam masyarakat, dan membantu harmonisasi di antara kelompok-kelompok yang berseteru pandangan.

Secara sosiologis, setiap masyarakat dari yang paling primitive hingga yang terkompleks, sistem media komunikasi mereka menjalankan fungsi seperti dinyatakan Harold Lasswell yaitu penjagaan lingkungan yang mendukung, pengaitan berbagai komponen masyarakat agar dapat menyesuaikan diri dengan perubahan lingkungan, serta pengalihan warisan sosial. Wilbur Schramm menggunakan istilah penjaga, forum, guru dan wahana hiburan. Fungsi positif media ini senada dengan fungsi rumah, gereja, dan sekolah-sekolah dalam mewariskan nilai kebudayaan (Rivers, William L., et. al., 2008).

Pada level social politik, dinamika peran media massa menciptakan opini public. Dalam pandangan Walter Lippman (1922) opini media menjadi efektif dan dipersepsi secara serius oleh masyarakat sebagai potret realitas yang terjadi. Ia dibentuk media, diperebutkan elit politik, tetapi akhirnya penuh dengan kepen- 
tingan ideologis dan menghegemoni massa (Ranciere, 2011). Senada, asumsi opini publik mempengaruhi persepsi publik dengan jangkauan yang sangat luas tanpa mengenal siapa dan dari mana seseorang berasal dikenal dalam kajian media klasik. Media massa diasumsikan memiliki kekuatan ibarat tembakan peluru dan jarum suntik sehingga publik akan tertembak dan tersuntik oleh opini media massa. Asumsi klasik ini dikritik bahwa media hanya punya efek terbatas yang berujung pada opinion leaders, lalu dikuatkan dalam peran agenda setting yang mengontrol persepsi publik. Apa yang ditayangkan, diberitakan, dan direpresentasikan oleh media massa maka itulah yang akan menjadi persepsi publik (Gurevitch et al, 2005).

Opini publik adalah domain yang sangat politis dan diintensifkan oleh tim kajian strategis (Lippman, 1922). Di AS pada era Bush, politik opini publik dikonstruksi dan didominasi oleh kelompok neokonservatif. Kelompok ini dalam membangun opini publik menggunakan enam media massa yaitu: The Weekly Standard: majalah politik terbit sejak 18 september 1995, terbit 48 kali setiap tahun, Commentary: sejak 1945, rumah intelektual neokonservatif, The National Interest: jurnal international affairs sejak 1985, Public Interest: jurnal budaya dan politik sejak 1965, National Review: sejak 1955, majalah politik konservatif, FrontPageMag.com: jaringan online. Lebih jauh, Eduard Depari mengatakan bahwa keistemewaan media dalam proses politik konstruksi opini publik di AS dapat dilihat dalam: pertama, melaporkan peristiwa politik kepada publik. Kedua, melakukan agenda setting, yakni menentukan isu-isu yang perlu ditanamkan. Ketiga, mengembangkan opini publik. Dan keempat, mengukur opini publik melalui polling dan melaporkan kembali kepada publik (Mubah 2007).
Proses mengetahui opini publik setidaknya bisa diawali dari mengetahui mekanisme kerja media massa sebab opini publik adalah produk media massa. Mengetahui media massa dapat dilakukan dengan mengajukan beberapa pertanyaan kritis berkaitan dengan pesan media yaitu bagaimana media dikonstruksi, apa nilai di balik pesan media, apa konvensi yang digunakan dalam media tersebut, siapa audiens yang dituju oleh media, siapa yang memiliki media, siapa yang diuntungkan oleh pesan media tersebut (Doyle, 2002; Adiputra, 2006).

Opini publik pra media sosial sangat efektif diperankan oleh televisi dan surat kabar. Penelitian terhadap televisi relatif dinamis di Indonesia misalnya Philip Kitley (2000) melacak peran televisi dalam mengenalkan dan membangun identitas budaya bangsa Indonesia di era Suharto atau Ariel Heryanto (2008) dalam mengurai cairnya identitas budaya bangsa pasca era otoriter Suharto yang terlihat dalam content budaya pop televisi. Namun, penelitian terhadap wajah dan peran televisi lokal masih relatif minim.

Jelang pilkada Sumbar 2010, representas politik lokal ditemui dalam program televisi lokal Padang TV yang menjadi media kampanye dan dialog politik para kandidat Gubernur, Walikota dan Bupati. Model komunikasi yang tercitrakan dalam televisi ini adalah hibriditas politik dan identitas kebudayaan. Terdapat proses mediatisasi politik, social dan kebudayaan (Hjarvard, 2008). Televisi lokal ini dalam program siarannya berperan tak hanya menjadi media strategis kampanye tapi sekaligus wahana dominan mendialogkan identitas modern publik Minangkabau.

Tak jauh berbeda dengan televisi, pembacaan terhadap representasi surat kabar melahirkan banyak kemungkinan identitas dan relasi pula yang tergambar jelas dalam rubrik berita. Salah satu 
rubrik yang mendapat perhatian publik adalah rubrik berita politik. Identitas dan relasi politik dapat ditemukan dalam rubrik ini. Paling tidak, kehadiran rubrik politik Harian Singgalang bisa dibaca sebagai respon demokratis-lokalitas media ini menjadi referensi masyarakat Sumatra Barat dalam memahami isu actual politik lokal Sumatra Barat atau sebagai institusi dominan kuasa media dan ruang aktualisasi elit politik. Yang jelas, baik Padang TV maupun Harian Singgalang menghasilkan wacana yang berbeda dengan karakter pesan media dan ekonomi politik di balik kedua insitusi media tersebut.

Berkaitan dengan isu keberpihakan media, secara umum televisi di Indonesia cenderung berpihak kepada partai politik pemilik modalnya seperti TV One atau Metro TV sedangkan surat kabar masih lebih terlihat professional independen. Hal ini sedikit berbeda dalam analisis McNair (2000) dengan formasi media di Inggris di mana surat kabar cenderung bias politik kepentingan daripada media televisi yang lebih professional mengutamakan publik seperti BBC. Potret politik media ini akhirnya menjadi realitas yang menarik dikaji untuk menemukan perspektif baru di balik eksistensi media massa.

Media massa dirancang untuk meningkatkan jangkauan, kecepatan, partisipasi dan efisiensi komunikasi. Teoretisi demokrasi percaya bahwa demokrasi terpelihara karena adanya partisipasi public yang aktif dalam kehidupan politik dan peduli dengan civic affairs (Dahlan, 1999). Di era yang makin canggih, media massa terutama televisi dan surat kabar menciptakan wajah baru teater demokrasi. Proses demokrasi modern dilangsungkan actor demokrasi dengan bantuan panggung media massa (Manin, 1997).

Studi sebelumnya mengenai efek media massa dalam pemilu terkait dengan perilaku memilih (Lazarsfeld et al, 1948, Berelson et al, 1954, Trenaman and McQuail (1961). Beberapa studi eksperimental (Hovland, Lumsdainet \& Shefield, 1949) dan survai dalam skala besar (Joseph Klapper, 1960). Pergeseran sikap dan opini politik, tampaknya bersifat terbatas seiring kuatnya norma kelompok dan stabilitas aliansi partai (Gurevitch et al, 2005). Di samping itu, isu mediatisasi politik juga layak untuk dicermati (Hjarvard, 2008; Manin, 1997; Brants and Voltmer, 2011).

Dalam memotret studi kasus Pemilukada Sumbar 2010 menggunakan model variasi koleksi data (Cassel \& Simon, 2004; Cresswell, 2007), baik studi literature, wawancara terstruktur, document media dan organisasi relevan dan terutama teks program media yang dibedah dengan metode analisis wacana kritis Norman Fairclough. Media dalam konteks analisis wacana kritis selalu berhubungan dengan ideologi dan kuasa. Hal ini berkaitan dengan cara bagaimana sebuah realitas wacana atau teks ditafsirkan dan dimaknai dengan cara pandang tertentu. Praktik wacana juga berkaitan dengan struktur dan relasi dalam masyarakat (Fairclough, 1995). Studi wacana media meliputi tiga objek dengan skala level masing-masing, yaitu teks yang bersifat mikro, praktik diskursus pada level meso dan praktik sosiokultural yang berada di level makro. Kerangka teoritis semacam ini adalah kerangka teoritis yang dikembangkan oleh Norman Fairclough (Eriyanto, 2001). Namun, model ini terlihat sangat linguisticoriented sehingga model analisis yang bersifat lebih utuh masih relative diperlukan misalnya dengan menggunakan analisis mediatisasi sebagai proses meningginya keterlibatan media secara politik sosiokulural dalam membentuk dan mempengaruhi struktur dan relasi social kebudayaan (Hjarvard, 2008). 


\section{Program Sumbar Satu dan Lokalitas Peran Padang TV}

Siaran Pemilukada Padang TV dapat disaksikan dalam program Alek Demokrasi yang merupakan live event Pemilukada, Detak Sumbar-Detak Pilkada yang berisi liputan sejak persiapan hingga pemilihan hari $\mathrm{H}$. Program siaran Pemilukada lainnya adalah Menuju Sumbar Satu yang diputar sekali dalam seminggu selama 30 Menit. Siaran ini memotret strategi kandidat Gubernur-Wakil Gubernur Sumbar memenangkan Pemilukada. Di samping itu, Padang TV juga memiliki live event yaitu Real Count Pemilukada, program Sumarak Kampuang yang bernuansa hiburan dan diadakan hanya sekali di Payakumbuh atas inisiatif calon gubernur Endang Irzal, dan pernah mengadakan Debat Wakil Gubernur bekerjasama dengan KPU Sumbar di Taman Budaya.

Target Padang TV dalam program siaran Pemilukada adalah berusaha melakukan pendidikan politik bagi masyarakat di Sumatra Barat, terutama masyarakat kota Padang agar lebih mengenali calon pemimpin mereka, terutama calon gubernur-wakil gubernur Sumbar dan tidak salah dalam menentukan pilihan dalam Pemilukada 30 Juni 2010. Padang TV sebagai media profesional di Sumatra Barat bersikap independen, netral dan berinisiatif untuk menjadi saluran Pemilukada 2010 di Sumatra Barat. Padang TV ingin menciptakan dialog interaktif dan kritis terhadap kandidat, walaupun kandidat beriklan di Padang TV (Fina, wawancara 2010).

Isu-isu Pemilukada yang disorot oleh Padang TV adalah kesiapan Komisi Pemilihan Umum melakukan Pemilukada, kisruh DPT, etika politik kandidat yang pragmatis, persiapan tim sukses, masa kampanye, tata cara dan pelaksanaan Pemilukada serta isu Black Campaign. Sementara itu, pemberitaan yang paling tinggi adalah pemilihan Gubernur. Kebijakan redaksional dalam memberitakan kandidat proporsional kecuali kandidat yang beriklan di Padang TV.

Pelaksanaan Pemilukada Sumbar 2010 dalam pandangan Delfi Mahyeldi (wawancara, 2010) wakil pimpinan redaksi Padang TV merepresentasikan kualitas demokrasi yang telah matang di tengah masyarakat Sumbar sehingga tidak terjadi konflik, yang dipengaruhi oleh faktor masyarakat yang cerdas, figur yang baik, dan pola pikir yang realistis.

Secara khusus, strategi politik media dan dialog identitas lokal dapat disaksikan dalam program Siaran Menuju Sumbar Satu di Padang TV yang memaparkan strategi kampanye dan pencitraan Cagub-Cawagub Sumbar 2010. Program ini bertajuk Menakar Pola Kampanye Calon Gubernur dan Wakil Gubernur Sumbar.

Program Menuju Sumbar dibuka dengan ikon Rumah Gadang sebagai symbol identitas Minangkabau dalam balutan siluet warna merah, kuning dan hitam serta alunan musik tradisional. Ikon Rumah Gadang, balutan warna dan musik Minangkabau kemudian menjadi indeks program Menuju Sumbar Satu. Ikon dan simbol Minangkabau ini selanjutnya tertera di layar televisi selama program berlangsung.

Program ini diawali dengan latar deklarasi Pemilu Badunsanak Senin, 10 Mei 2010 yang menghadirkan Menteri Dalam Negeri Gamawan Fauzi, Ketua KPU Pusat M. Hafidz Anshari dan para kontestan Pemilukada Sumbar 2010 pada saat itu. Kemudian secara paradigmatis, kandidat-kandidat Gubernur-Wakil Gubernur Sumbar perlahan mulai terlihat satu per satu sesuai dengan nomor urut mereka untuk membubuhkan tanda tangan kesepakatan Pemilu Badunsanak. Dimulai dari nomor urut 1 pasangan Ediwarman-Husni Hadi, nomor urut 2 
Marlis Rahman-Aristo Munandar (MATO), nomor urut 3 Irwan PrayitnoMusliar Kasim, nomor urut 4 Endang Irzal-Asrul Syukur dan nomor urut 5 Fauzi Bahar-Yohanes Dahlan.

Selanjutnya program ini menampilkan kandidat Gubernur nomor urut 3 yaitu Irwan Prayitno yang berada di tengah-tengah pendukungnya dalam kampanye terbuka di sebuah lapangan besar. Kemudian disusul dengan kandidat nomor urut 2 MATO yang memperlihatkan kandidat ini bersama tokoh partai dan massa pendukung. Dilanjutkan dengan kandidat nomor urut 5 Fauzi Bahar yang terlihat berada di tengah kerumunan massa. Lalu dilanjukan dengan nomor urur 4 Endang Irzal yang terlihat berada di atas panggung berkampanye di depan khalayak pendukungnya. Ganjilnya, pembukaan program siaran ini menonjolkan kandidat gubernur tanpa wakil gubernur, meriahnya simbol partai pendukung, tidak terlihatnya kontestan nomor urut 1 yaitu pasangan Ediwarman-Husni Hadi, dan afirmasi memori yang dilakukan dengan menayangkan kembali ikon, indeks dan simbol kampanye kandidat gubernur-wakil gubernur Sumbar 2010.

Secara kronologis-sintagmatis, kandidat gubernur-wakil gubernur ditampilkan secara berulang bersama symbol charismatik dan pendukung berat masing-masing. Melalui program TV lokal ini dapat diketahui bahwa strategi dan momentum kampanye kandidat gubernurwakil gubernur Sumbar 2010 ini dilakukan melalui media massa, kampanye massal, pemasangan atribut, dan kunjungan langsung ke masyarakat. Yang paling banyak dilakukan adalah kampanye melalui pemasangan atribut fisik, kemudian kampanye melalui media massa.

Program ini sedikit memperlihatkan kandidat nomor urut 1 EdiwarmanHusni Hadi melakukan kampanye melalui media massa dan pemasangan atribut secukupnya, namun tidak melakukan kampanye kunjungan langsung secara terbuka, baik ke tempat tinggal masyarakat maupun kampanye di depan massa pendukung. Ini berbeda dengan pasangan nomor urut 2 MATO yang memaksimalkan semua potensi dalam berkampanye, baik kampanye melalui media massa, pemasangan atribut, maupun silaturahim langsung dengan masyarakat. Strategi kampanye nomor urut 3 Irwan-MK juga menggunakan semua saluran yang ada, baik media massa (cetak, elektronik, dan online), pemasangan atribut (baliho, spanduk, stiker), maupun kunjungan langsung (door to door, direct selling) ke rumah masyarakat di seluruh daerah. Strategi kampanye Endang Irzal-Asrul Syukur juga mengikuti pola MATO dan Irwan-MK dengan menggunakan media massa, pemasangan atribut dan kunjungan langsung (heart to heart). Berbeda dengan nomor urut 5 Fauzi Bahar banyak melakukan kampanye simpatik (head to head/face to face) dengan kunjungan langsung menggunakan helikopter untuk mengakses daerah terpencil. Efektivitas menjadi pertimbangan utama sehingga kandidat ini melakukan kampanye head to head.

Program acara Menuju Sumbar Satu Padang TV ini menunjukkan bahwa politik opini publik direpresentasikan oleh media dengan menghadirkan kandidat gubernur-wakil gubernur beserta tim suksesnya dalam strategi politikkebudayaan dan momentum kampanye untuk kepentingan menarik simpatik dan membentuk citra positif ketokohan sesaat mereka sehingga terpilih dalam Pemilukada 30 Juni 2010. Di samping itu, kampanye menjadi efektif dalam kunjungan langsung ke tengah masyarakat, yang dibarengi dengan media massa dan pemasangan atribut sosialisasi disertai manajemen kampanye yang baik 
dan sistematis sebagaimana dilakukan nomor urut 3 Irwan Prayitno-Muslim Kasim sehingga terpilih sebagai Gubernur-wakil Gubernur Sumbar.

\section{Politik Opini Publik dalam Headline dan Laporan Khusus Singgalang}

Strategi politik media kandidat Pemilukada Sumbar 2010 untuk mencitrakan diri di depan masyarakat sebagai calon pemimpin ideal, merakyat, visioner dan dapat memajukan daerah terlihat dalam Headline dan Laporan Khusus Singgalang secara massif dan intensif di periode April, Mei dan Juni 2010. Kepentingan kontestan di tiga bulan ini agar masyarakat memilih mereka dalam Pemilukada 30 Juni 2010. Ini berbeda di periode Juli dan Agustus 2010, politik pencitraan kandidat menurun drastis sebab Pemilukada telah dilakukan. Opini publik ini dengan mudah bergeser menjadi opini hukum, konflik dan kepentingan kandidat untuk menggugat hasil Pemilukada di dua bulan pasca Pemilukada 2010.

Secara umum, proses reportase Headline Utama dan Laporan Khusus Singgalang mengangkat tema yang aktual di Sumatra Barat yaitu pesta demokrasi Pemilukada 2010 pemilu badunsanak yang dibalut identitas Minangkabau. Ini dapat terlihat dalam fase awal pendaftaran hingga masa kampanye.

\section{Tabel 1. Representasi Headline dan Laporan Khusus Singgalang dalam Pemilukada Sumbar 2010 (Diolah Penulis dari Koran Singgalang)}

\begin{tabular}{|c|c|c|c|}
\hline Periode & Headline & Lapsus & Keterangan \\
\hline $\begin{array}{l}\text { Periode } \\
\text { April 2o1o: } \\
\text { Masa Gegap } \\
\text { Gempita Di } \\
\text { Tahap } \\
\text { Pendaftaran } \\
\text { Dan } \\
\text { Penetapan } \\
\text { Kandidat }\end{array}$ & $\begin{array}{l}\text { Pada Kamis, } 8 \text { April } 2010 \text { (23 Rabiul } \\
\text { Akhir 1431 H), Singgalang } \\
\text { menurunkan headline Pemilukada } \\
\text { yang ditempatkan pada bagian atas } \\
\text { yaitu berita berjudul Marlis dan Fauzi } \\
\text { Mendaftar Gembira Ria ke KPU } \\
\text { berdampingan dengan rubrik } \\
\text { advetorial berjudul Genderang } \\
\text { Pilkada Sumatra Barat. Dalam } \\
\text { representasi berita pertama yang } \\
\text { berjudul Marlis dan Fauzi Mendaftar } \\
\text { Gembira Ria ke KPU, dua kandidat } \\
\text { gubernur-wakil gubernur yaitu } \\
\text { Pasangan Marlis Rahman-Aristo } \\
\text { Munandar dan pasangan Fauzi } \\
\text { Bahar-Yohannes pahlan } \\
\text { digambarkan secara positif sebagai } \\
\text { dua pasang calon gubernur-wakil } \\
\text { gubernur yang gagah, ramah dan } \\
\text { penuh kesiapan menuju KPU untuk } \\
\text { mendaftar sebagai kontestan } \\
\text { Pemilukada 2010. Berita tertulis ini } \\
\text { dikuatkan dengan foto kedua } \\
\text { pasangan kandidat gubernur-calon } \\
\text { wakil gubernur ini. }\end{array}$ & $\begin{array}{l}\text { Laporan Khusus, Kamis } 8 \text { April } \\
2010 \text { menurunkan banyak berita } \\
\text { tentang kontestan Pemilukada } \\
\text { Sumbar } 2010 \text { di halaman berbeda. } \\
\text { Pada Laporan Khusus pertama } \\
\text { diturunkan dalam tiga judul: } \\
\text { pertama, berita dengan judul } \\
\text { Pendaftaran Benny Utama-Daniel } \\
\text { Lubis Semarak. Dalam angle } \\
\text { berita, pasangan kandidat bupati } \\
\text { dan wakil bupati Pasaman ini } \\
\text { ditampilkan penuh kemeriahan } \\
\text { menuju KPU untuk mendaftarkan } \\
\text { diri sebagai kontestan Pemilukada } \\
\text { Kab. Pasaman. Dalam tubuh } \\
\text { berita, mereka direpresentasikan } \\
\text { sebagai kandidat yang populis dan } \\
\text { memahami budaya rakyat dengan } \\
\text { dukungan massa besar yang } \\
\text { berasal dari berbagai elemen } \\
\text { masyarakat di Pasaman. }\end{array}$ & $\begin{array}{l}\text { Cara } \\
\text { pemberitaan } \\
\text { pada headline } \\
\text { dan lapsus ini } \\
\text { sangat bombastis } \\
\text { menyambut } \\
\text { pemilukada } \\
\text { sumbar } 2010 \text { dan } \\
\text { dalam } \\
\text { menampilkan } \\
\text { figur kandidat. }\end{array}$ \\
\hline
\end{tabular}



Sumatra Barat 2010 pada Koran Singgalang dan Program Sumbar Satu

\begin{tabular}{|c|c|c|c|}
\hline Periode & Headline & Lapsus & Keterangan \\
\hline $\begin{array}{l}\text { Periode Mei } \\
\text { 201o: } \\
\text { Pemilu } \\
\text { Badunsanak } \\
\text { dan } \\
\text { Sosialisasi } \\
\text { Simpatik } \\
\text { Kandidat }\end{array}$ & $\begin{array}{l}\text { Singgalang, Selasa 11 Mei } 2010 \text { (27 } \\
\text { Jumadil Awal 1431 H) menurunkan } \\
\text { Headline Pilkada Badunsanak } \\
\text { Dilaunching: Sumbar Terbesar Calon } \\
136 \text { Orang. Dalam angle berita } \\
\text { digambarkan Pemilukada Sumbar } \\
\text { 2010 yang dilaunching di Kantor } \\
\text { Gubernur Sumbar } \text { sebagai } \\
\text { Pemilukada terbesar di Indonesia. } \\
\text { Dalam tubuh rerita } \\
\text { direpresentasikan tema Pemilukada } \\
\text { Sumbar yaitu Pamilu } \\
\text { Badunsanak, Damai dan } \\
\text { Berkualitas. Dalam berita foto } \\
\text { terlihat Mendagri Gamawan Fauzi } \\
\text { didampingi Ketua KPU Pusat, } \\
\text { Kapolda Sumbar dan para Kontestan } \\
\text { Pemilukada sedang membubuhkan } \\
\text { tanda tangan pada sebuah baliho } \\
\text { pilkada badunsanak Sumbar. }\end{array}$ & $\begin{array}{l}\text { Singgalang, Selasa } 11 \text { Mei } 2010 \\
\text { menurunkan Laporan Khusus } \\
\text { dalam tiga judul berita. Pertama, } \\
\text { berita berjudul Irfendi-Zadri } \\
\text { Mencuat Bagaikan Roket. Dalam } \\
\text { angle dan tubuh berita, kandidat } \\
\text { ini direprsesentasikan memiliki } \\
\text { kedekatan dengan tokoh } \\
\text { masyarakat dan masyarakat awam, } \\
\text { tampil bersahaja dan memiliki } \\
\text { keinginan untuk memajukan } \\
\text { daerah. Berita kedua berjudul } \\
\text { Nafas Pembangunan Ditunggu } \\
\text { Kampuang dan Parantauan: Ingin } \\
\text { Bangkit dan Jaya, Coblos Nomor } \\
\text { Tiga. Dalam tubuh berita, Irfendi- } \\
\text { Zadri ditampilkan sebagai } \\
\text { kandidat yang diharapkan dan } \\
\text { ditunggu masyarakat sebab } \\
\text { kandidat ini memiliki jaringan } \\
\text { yang luas. Berita ketiga berjudul } \\
\text { Akar Rumput Bergembira: Cabup } \\
\text { Irfendi Lah Patuik Jadi Bupati. } \\
\text { Dalam tubuh berita, kandidat } \\
\text { diasumsikan memiliki kedekatan } \\
\text { dengan akar rumput, tanggap } \\
\text { terhadap bencana, dan sosok yang } \\
\text { diidolakan }\end{array}$ & $\begin{array}{l}\text { Headline dan } \\
\text { lapsus } \\
\text { membangun } \\
\text { opini pemilu } \\
\text { Badunsanak dan } \\
\text { memperkenalkan } \\
\text { lebih jauh } \\
\text { kapasitas para } \\
\text { kandidat }\end{array}$ \\
\hline
\end{tabular}

Reportase politik Singgalang dalam Headline utama dan rubrik Laporan Khusus terlihat mengkonstruksi opini ketokohan calon pemimpin di Sumatra Barat. Bahkan, Singgalang dengan segenap sumber daya profesional dan misi institusinya mencoba mengarahkan opini tersebut untuk memengaruhi khalayak dalam proses politik demi mengenalkan semua kandidat kepada khalayak agar berpartisipasi dalam Pemilukada Sumbar 2010. Uniknya, upaya politis ini berbarengan dengan komitmen Singgalang sebagai pilar demokrasi di Sumatra Barat untuk terlibat dalam menentukan masa depan politik di Sumatra Barat. 


\section{Tabel 2. Representasi Headline dan Laporan Khusus Singgalang dalam Pemilukada Sumbar 2010 (Diolah Penulis dari Koran Singgalang)}

\begin{tabular}{|c|c|c|c|}
\hline Periode & Headline & Lapsus & Keterangan \\
\hline $\begin{array}{l}\text { Periode Juni } \\
\text { 2o1o: } \\
\text { Debat } \\
\text { Kandidat, } \\
\text { Kampanye } \\
\text { Terbuka } \\
\text { hingga Hari } \\
\text { Pemilihan }\end{array}$ & $\begin{array}{l}\text { Singgalang, Selasa } 15 \text { Juni } 2010 \text { ( } 26 \\
\text { Jumadil Akhir } 1431 \mathrm{H} \text { ) menurunkan } \\
\text { headline Pemilukada berjudul Cagub } \\
\text { Sumbar Saling Sindir. Dalam tubuh } \\
\text { berita, debat kandidat gubernur- } \\
\text { wakil gubernur digambarkan untuk } \\
\text { pertama kalinya disiarkan secara live } \\
\text { di televisi swasta nasional di mana } \\
\text { kontestan saling menyindir. Berita } \\
\text { ini dikuatkan dengan berita foto yang } \\
\text { memperlihatkan para kandidat } \\
\text { gubernur-wakil gubernur tampil } \\
\text { dalam debat kandidat yang } \\
\text { diselenggarakan TVOne bekerjasama } \\
\text { dengan Harian Singgalang.s }\end{array}$ & $\begin{array}{l}\text { Singgalang Sabtu, } 26 \text { Juni } 2010 \text { (14 } \\
\text { Rajab 1431 H) Laporan Khusus } \\
\text { pertama di edisi ini menurunkan } \\
\text { judul Fauzi Hilang di Tengah } \\
\text { Lautan Massa. Dalam berita ini, } \\
\text { Fauzi semakin disambut antusias } \\
\text { oleh masyarakat. Berita ini } \\
\text { didukung oleh foto yang } \\
\text { memperlihatkan Fauzi bersama } \\
\text { masyarakat. }\end{array}$ & $\begin{array}{l}\text { Headline } \\
\text { mengeritik } \\
\text { budaya politik } \\
\text { saling sindir } \\
\text { sedangkan } \\
\text { lipsus } \\
\text { menampilkan } \\
\text { kampanye } \\
\text { terbuka para } \\
\text { kandidat yang } \\
\text { mencari } \\
\text { simpati rakyat }\end{array}$ \\
\hline $\begin{array}{l}\text { Periode Juli } \\
\text { 2010: } \\
\text { Penghitungan } \\
\text { Suara, } \\
\text { Penetapan } \\
\text { Hasil dan } \\
\text { Masa } \\
\text { Gugatan }\end{array}$ & $\begin{array}{l}\text { Singgalang, Kamis } 1 \text { Juli } 2010 \text { (19 } \\
\text { Rajab } 1431 \mathrm{H} \text { ) menurunkan Headline } \\
\text { utama berjudul Bisa Saja Dua } \\
\text { Putaran: Sementara Irwan Unggul. } \\
\text { Dalam angle dan tubuh berita } \\
\text { digambarkan bahwa Irwan-MK } \\
\text { untuk sementara masih unggul } \\
\text { dalam Pemilukada gubernur-wakil } \\
\text { gubernur Sumbar. Namun, opsi } \\
\text { putaran kedua masih terbuka. } \\
\text { Sementara headline selanjutnya } \\
\text { berjudul Terima Hasil Pilkada } \\
\text { dengan Lapang Dada, dan Pilkada } \\
\text { Bupati dan Wakil Walikota: Kejar- } \\
\text { kejaran di Seluruh Daerah. } \\
\text { Singgalang, Jumat 30 Juli 2010 (18 } \\
\text { Syaban 1431 H) menurunkan } \\
\text { Headline berjudul Ketua Mahkamah } \\
\text { Konstitusi: Orang Asing Boleh di } \\
\text { Tempat Kampanye. }\end{array}$ & $\begin{array}{l}\text { Di periode Juli } 2010 \text { ini, Laporan } \\
\text { Khusus tidak lagi memotret } \\
\text { Pemilukada seperti periode April, } \\
\text { Mei dan Juni 2010. Berita } \\
\text { Pemilukada hanya dicover oleh } \\
\text { Headline utama dan rubrik } \\
\text { Singgalang lainnya. Ini berkaitan } \\
\text { dengan isu Pemilukada yang makin } \\
\text { mengecil pada berita hasil } \\
\text { Pemilukada Sumbar 2010. }\end{array}$ & $\begin{array}{l}\text { Headline } \\
\text { memberitakan } \\
\text { kemenangan } \\
\text { kandidat dan } \\
\text { gugatan hingga } \\
\text { ke MK, } \\
\text { sedangkan } \\
\text { lipsus mulai } \\
\text { beralih ke isu } \\
\text { lain }\end{array}$ \\
\hline $\begin{array}{l}\text { Periode } \\
\text { Agustus } \\
\text { 2010: } \\
\text { Keputusan } \\
\text { MK, } \\
\text { Pelantikan } \\
\text { dan Tugas } \\
\text { Baru }\end{array}$ & $\begin{array}{l}\text { Singgalang, Jumat } 6 \text { Agustus } 2010 \\
\text { (25 Syaban 1431 H) menurunkan } \\
\text { Headline dengan judul MK } \\
\text { Menangkan KPU Sumbar. Dalam } \\
\text { angle dan tubuh berita digambarkan } \\
\text { bahwa gugatan kubu Marlis Rahman- } \\
\text { Aristo Munandar dan Ediwarman- } \\
\text { Husni Hadi terhadap putusan KPU } \\
\text { Sumbar ditolak MK karena tidak } \\
\text { dapat dibuktikan dengan baik. } \\
\text { Gubernur-Wakil Gubernur terpilih, } \\
\text { Irwan Prayitno-Muslim Kasim } \\
\text { tinggal dilantik 15 Agustus } \\
\text { mendatang. }\end{array}$ & $\begin{array}{l}\text { Laporan } \text { Khusus Singgalang } \\
\text { Minggu, 15 Agustus 2010 } \\
\text { menurunkan tiga berita. Pertama, } \\
\text { berita utama berjudul Dua Datuk } \\
\text { Pimpin Sumbar. Berita kedua } \\
\text { berjudul Komentar dan Opini } \\
\text { Tokoh tentang H. Muslim Kasim. } \\
\text { Berita ketiga berjudul Beri } \\
\text { Dukungan Gubernur Terpilih. } \\
\text { Berita ini dilengkapi foto Irwan } \\
\text { Prayitno dan Muslim Kasim } \\
\text { sehingga menguatkan ketokohan } \\
\text { mereka. }\end{array}$ & $\begin{array}{l}\text { Headline } \\
\text { menampilkan } \\
\text { akhir sengketa } \\
\text { pemilukada } \\
\text { dengan keme- } \\
\text { nangan Irwan } \\
\text { Prayitno dan } \\
\text { Muslim Kasim } \\
\text { dan kebesaran } \\
\text { jiwa kandidat } \\
\text { lainnya, sedang } \\
\text { Lipsus menam- } \\
\text { pilkan figure } \\
\text { terpilih ber- } \\
\text { sama tokoh } \\
\text { masyarakat }\end{array}$ \\
\hline
\end{tabular}




\section{Respon audiens}

Menarik mengamati respon beragam kalangan atas peran media lokal dalam Pemilukada yang secara umum mengapresiasi peran media dan bangkitnya demokrasi lokal. Misalnya dalam pandangan Ade, mahasiswa (wawancara, 10 September 2010). "media massa terutama Harian Singgalang dan Padang TV telah menjadi media sosialisasi dan alat kampanye yang efektif bagi kontestan Pemilukada Sumbar 2010. Media massa menutupi minimnya sosialisasi Pemilukada oleh Komisi Pemilihan Umum. Media sangat berpengaruh kepada masyarakat yang memiliki akses terhadap media dan tidak sebaliknya. Namun, Padang TV dan Harian Singgalang dalam Pemilukada Sumbar 2010 cenderung berpihak kepada kandidat tertentu. Ini terlihat dalam liputan dan pemberitaannya yang terkesan berlebihan dalam menampilkan kontestan Pemilukada".

Senada dengan pandangan ini, Roni, mahasiswa (wawancara, 10 September 2010) memandang "Padang $T V$ dan Harian Singgalang memiliki pengaruh besar dalam mempopulerkan kandidat kepada masyarakat". Hal ini juga diaminkan oleh Novi, mahasiswi (wawancara, 12 September 2010), bahwa "peran Padang TV dan Harian Singgalang dalam Pemilukada Sumbar 2010 adalah menyampaikan informasi tentang kandidat dan mempengaruhi pilihan masyarakat."

Ernita Arif, akademisi (wawancara, 15 September 2010), "Pemilukada Sumbar 2010 telah diliput oleh media dengan baik, terutama media cetak seperti Harian Singgalang. Lebih jauh, demokrasi lokal telah dirayakan dengan baik berkat bantuan Media Massa di Sumatra Barat." Pandangan ini dipertajam oleh Virtous Setyaka, akademisi (wawancara, 15 September 2010), bahwa "performance Pemilukada
Sumbar 2010 seperti yang diliput media lokal, sangat menarik sebab telah melahirkan wajah baru yang turun dari pusat ke daerah. Kemenangan Irwan Prayitno sebagai Gubernur Sumbar dalam Pemilukada 2010 tentu didukung oleh kekuatan politik PKS yang solid. Namun, liputan Padang TV dan pemberitaan Singgalang tidak benarbenar independen melihat kepentingan bisnis media mereka."

Dalam pandangan Heru, Wartawan (wawancara, 17 September 2010), "media dalam Pemilukada Sumbar 2010 selalu mencoba konsisten dalam pemberitaan yang berpihak kepada kepentingan publik. Namun demikian, media tidak dapat lepas dari kepentingan bisnis yang berkaitan dengan momentum. Sebab media harus tetap eksis untuk memperjuangkan idealismenya." Hal ini juga disampaikan oleh Haris, Freelance (wawancara, 17 September 2010) bahwa "Padang TV dan Singgalang telah melakukan tugasnya sesuai dengan peran dan tanggung jawab mereka dalam Pemilukada Sumbar 2010. Media mapan tentu saja lebih menjaga kualitas di depan publik.”

Dalam pandangan Welly, pedagang (wawancara, 16 September 2010) bahwa "media lokal semisal Padang TV dan Singgalang tentu tak melewatkan momentum Pemilukada 2010. Ada berita yang baik, ada pula beritanya yang buruk. Namun, pemberitaan yang baik lebih banyak, terutama memberi informasi seputar Pemilukada." Senada, Ovi, pelayan tokoh (wawancara, 17 September 2010) bahwa "pemberitaan di media lokal tentang Pemilukada Sumbar 2010 masih lebih banyak yang baik dalam memberikan informasi yang kita butuhkan dalam mengenali calon pemimpin di Sumbar." Menurut Chalik, PNS (wawancara, 14 September 2010) "Pemilukada Sumbar 2010 telah berlangsung dengan baik. 
Salah satu yang berperan adalah media lokal seperti Padang TV dan Singgalang."Persepsi ini tidak berbeda dalam pandangan Budi, PNS (wawancara, 14 September 2010) bahwa "Pemilukada Sumbar 2010 telah menghasilkan pemimpin di Sumbar berkat campur tangan media lokal."

\section{Kesimpulan}

Perhelatan Pemilukada Sumbar 2010 menuju kursi Gubernur-Wakil Gubernur, Bupati-Wakil Bupati, WalikotaWakil Walikota terlihat sangat dinamis dalam liputan media lokal. Ada interaksi antara media, elit politik dan masyarakat pemilih. Tak bisa dibayangkan kering dan lambannya proses politik tersebut tanpa peran media. Media massa local yaitu Padang TV dan Surat Kabar Singgalang dalam taraf tertentu telah berperan demokratis menyebar pesan beragam dan membentuk opini public serta perlahan membangun ruang public demokratis seputar liputan pemilu dengan memuat agenda dan profil kandidat dalam program siaran khusus seperti Menuju Sumbar Satu dan disetting dalam Headline Utama dan Laporan Khusus. Media lokal telah mengafirmasi peran sentralnya sebagai pilar keempat demokrasi.

Tentu saja, ini juga petanda meningginya nalar media dalam moment politik yang diperankan oleh Padang TV dan Singgalang. Hanya saja, pesan tekstual media lokal tersebut untuk beberapa taraf masih jelas menguatkan kepentingan sesaat elit kandidat yang berjalin kelindan dengan ekonomi politik media sehingga pandangan alternative media lokal masih harus disemai untuk menampilkan elit dan isu politik lainnya secara kritis serta terbuka menerima kritikan alternatif.

Program acara Menuju Sumbar Satu Padang TV ini menunjukkan bahwa politik opini publik dilakoni oleh kandidat gubernur-wakil gubernur beserta tim suksesnya dalam strategi teater politikkebudayaan di mana momentum kampanye bertujuan menarik simpatik dan membentuk citra positif ketokohan agar terpilih dalam Pemilukada 30 Juni 2010. Sedangkan Headline dan Laporan Khusus Singgalang yang merepresentasikan ketokohan para kandidat secara massif dan intensif di periode April, Mei dan Juni 2010 mengisyaratkan determinasi media lokal dan perlunya elit direpresentasikan atau dicitrakan oleh media untuk meraih efek magis opini public. Proses interpelasi ideologis media dan elit kandidat ini pun menurun drastis di periode Juli dan Agustus 2010.

Akhirnya, politik media oleh elit kandidat dalam beberapa taraf seperti dipotret oleh Padang TV dan Singgalang dapat dipahami juga sebagai politik konsensus dengan media lokal dilakukan demi kepentingan politik pragmatis. Publik pun berpartisipasi mengapresiasi apa yang terlihat dan ditampilkan secara positif oleh media. Namun, segera pasca Pemilukada terlihat kembali potret elit sesungguhnya bersengketa tanpa banyak memedulikan media dan citra publik mereka lagi 


\section{DAFTAR PUSTAKA}

Adiputra, W. M. 2006. Menyoal komunikasi memberdayakan masyarakat. Yogyakarta: Fisipol UGM.

Anderson, B. 2006. Imagined communities: Refelections on the origin and spread of Nationalism. London: Verso.

Bailey, S. 2005. Media audiences and identity: Self construction in the fan experience. New York: Palgrave Macmillan.

Brants, K.,\& Voltmer, K. 2011. Political communication in postmodern democracy: Challenging the primacy of politic. London: Palgrave Macmillan.

Burton, G. 2005. Media and society: Critical perspective. Glasgow: Open University Press.

Calhoun, C. ed. 1992. Habermas and the Public Sphere. Massachusetts: The MIT press

Castell, M. 2009.Communication Power. New York: Oxford Press.

Chan, J. 2001. Media, democracy and globalization: A comparative framaework. The public $103 \mathrm{Vol} .8$ (2001), 4, 103-118.

Coyne, C.J., \& Leeson, P.T. 2009. Media, development and institutional change. Massachusets: Edward Elgar.

Cresswell, J. W. 2007. Qualitative inquiry \& research design: Choosing among five approaches.California: Sage.

Curran, J. 2002. Media and power. London: Routledge.

Doyle, G. 2002. Media ownership. London: Sage.
Durham, M. G., \& Kellner, D. M. 2001. Media and cultural studies: Keyworks. Oxford: Blackwell Pubishing.

Eco, U. 2009. Tamasya dalam hiperrealitas. Yogyakarta: Jalasutra.

Fairclough, N.1995. Critical discourse analysis. London: Longman.

Eriyanto. 2001. Analisis wacana: Pengantar analisis teks media. Yogyakarta: LKiS.

2001. Language and power. London: Longman.

2006. Discourse and social change. Cambridge: Polity Press.

Fiske, J.1991. Introduction to communication studies. London: Routledge.

Gadamer, H. 1995. Truth and method. New York: Continum.

Golding, P., \& McChesney, R.W. 1997. The global media: The new missionaries of global capitalism. London: Cassell.

Gunther, R., \& Mughan, A. 2000. Democracy and the media; $A$ comparative perspective. Cambridge: Cambridge university press.

Gurevitch, Bennett, T., Curran, J., and Woollacott J. (eds) 2005. Culture, society and the media. London:Routledge.

Hadiz, V.R. 2005. Dinamika kekuasaan ekonomi politik Indonesia pasca Soeharto. Jakarta: LP3ES. 
Hamad, I. 2004. Konstruksi realitas politik di media massa: Sebuah study critical discourse analysis. Jakarta: Granit.

Hardiman, F., B. 1993. Menuju masyarakat komunikatif. Yogyakarta: Kanisius.

Hidayat, D.N.2000. Pers dalam revolusi Mei: Runtuhnya sebuah hegemoni. Jakarta: PT. Gramedia Pustaka Utama.

Hepp, A., et al. 2010. MediatizationEmpirical perspectives: An introduction to a special issue. Communications, 223_228 03412059/2O1O/O35_O223 DOI 10.1515/COMM.2010.012 .

Heryanto, A. 2008. Popular culture in Indonesia:Fluid identities in postauthoritarian politics. London: Routledge.

Hjarvard, S. 2008. The mediatization of society: A theory of the media as agents of social and cultural change. Nordicom Review 29 (2008) 2, pp. 105-134

Kim, Y. 2008. Media consumption and everyday life in Asia. New York: Routledge.

Kimura, E.2010. Indonesia in 2010. Asian survey, Vol. 51, No. 1.

Kitley, P. 2000. Television, nation, and culture in Indonesia. Athens: Ohio University Center for International Studies.

Lippmann, W. 1922. Public opinion . New York: Macmillan.

Littlejohn, S. W. 2002. Theories of human communication $5^{\text {th }}$ ed. Belmont, CA:Wadsworth.
Loon, V. J. 2008. Media technology: Critical perspective. New York: Open University Press

Manin, B. 1997. The principles of representative government. New York: Cambridge University Press

Marvasti, A., B. 2004. Qualitative research in Sociology: An introduction. London: Sage.

Maryani, E.2011. Media dan perubahan sosial.Bandung:Rosda.

McCargo, D.2003. Media and politics in Pacific Asia. London: Routledge Curzon.

McLuhan, M. 1964. Understanding media : The extensive of man. New York: McGraw-Hill.

McNair, B. 2000. Journalism and democracy: An evaluation of the political public sphere. London: Routledge.

McQuail, D. 1997. Mass communication theory An Introduction. London: Sage Publications.

Mubah, A. S. 2007. Menguak neokonservatif. Yogyakarta: Pustaka Pelajar

Moores, S. 2006. Media theory: Thingking about media and communication. New York: Routledge

Newcomb, H. 2000. Television: The critical reading. Oxford: Oxford University Press.

Pawito. 2007. Penelitian komunikasi kualitatif. Yogyakarta: LKis.

Piliang, Y., A. 2009. Posrealitas: Realitas kebudayaan dalam era posmetafisika.Yogyakarta:Jalasutra 
Ranciere, J. 2011. Althusser`s Lesson. London: Continum.

Rivers, W. L. et al. 2008. Media massa \& masyarakat modern. Jakarta: Kencana.

Rosengren, K.E. 1994. Media effect and beyond: Culture, socialization and lifestyles. London: Routledge

Ross, K., \& Nightingale, V. 2003. Media and audiences: New perspectives. Glasgow: Open University Press

Stoke, J. 2003. How to do media and cultural studies. London: Sage.

Stromback, J. 2008. Four phases of mediatization: An analysis of the mediatization of politics', The International Journal of Press/Politics 2008 13: 228 DOI: 10.1177/1940161208319097 The online version of this article can be found at: DOI: 10.1177/ 14614440222226244
Sardar, Z., dan Loon, B.V. 2008. Membongkar kuasa media. Yogyakarta: Resist Book

Vivian, J. 2008. Teori komunikasi massa. Jakarta: Kencana

Walton, D. 2007. Media argumentation. Cambridge: Cambrdige University press

Wayne, M. 2003. Marxism and media studies: Key concepts and contemporary trends. London: Pluto Press

Zakaria, Fareed. 2004. Masa Depan Kebebasan: Penyimpangan Demokrasi di Amerika dan Negara lain. Jakarta: Ina Publikatama.

Website

www.padangtoday.com/ 
Jurnal komunikasi, Volume 9, Nomor 1, Oktober 2014 